Editors' Note: In WriteClick this week, in reference to "A randomized trial of varenicline (Chantix) for the treatment of spinocerebellar ataxia type 3," Drs. Connolly et al. report on their own clinical experience using varenicline in patients with ataxia. In contrast to authors Zesiewicz et al., they found poor tolerability in their mixed ataxia population. Dr. AndradeMachado discusses his own findings of symmetric thalamic hypoperfusion without structural abnormalities in patients with atypical evolution of rolandic epilepsy, consistent with the results of Sánchez Fernández et al. in their article, "Early thalamic lesions in patients with sleep-potentiated epileptiform activity."

Megan Alcauskas, MD, and Robert C. Griggs, MD

\section{A RANDOMIZED TRIAL OF VARENICLINE (CHANTIX) FOR THE TREATMENT OF SPINOCEREBELLAR ATAXIA TYPE 3}

Barbara S. Connolly, L.K. Prashanth, Binit B. Shah, Connie Marras, Anthony E. Lang, Toronto: Zesiewicz et al. ${ }^{1}$ reported that varenicline improved ataxia in patients with spinocerebellar ataxia type 3 (SCA3) with excellent tolerance. We used open-label varenicline in a similar dosing schedule from 2 weeks to greater than 6 months in 7 patients with ataxia (3 SCA3, 1 multiple system atrophy with cerebellar features, 3 ataxia of unknown etiology).

Five patients discontinued treatment due to intolerable side effects: nausea, insomnia, lightheadedness, depression, and worsened unsteadiness. One patient tolerated but discontinued treatment after 5 weeks for lack of benefit and one continued treatment for over 6 months with very mild subjective gait improvement but had frequent nightmares.

We did not utilize standard rating scales for most patients, and although Zesiewicz et al. found improvements in scores, they also reported no change in patient or clinical global impression. They did not provide phenotype details. Studies have shown that stimulation of nicotine receptors results in dopamine release. ${ }^{2,3}$ Nigrostriatal degeneration with or without parkinsonism is a feature of SCA3; varenicline could increase dopamine levels, resulting in a modest improvement in motor function.

Varenicline was very poorly tolerated in our mixed ataxia population. The reason for this difference from the experience of Zesiewicz et al. is unclear. An impact on the dopaminergic system might explain some of the benefit documented by these investigators.

(C) 2012 American Academy of Neurology

1. Zesiewicz TA, Greenstein MB, Sullivan KL, et al. A randomized trial of varenicline (Chantix) for the treatment of spinocerebellar ataxia type 3. Neurology 2012;78:545-550.

2. Marshall DL, Redfern PH, Wonnacott S. Presynaptic nicotinic modulation of dopamine release in the three ascending pathways studied by in vivo microdialysis: comparison of naive and chronic nicotine-treated rats. J Neurochem 1997;68:1511-1519.

3. Maskos U. Role of endogenous acetylcholine in the control of the dopaminergic system via nicotinic receptors. J Neurochem 2010;114:641-646.

\section{EARLY THALAMIC LESIONS IN PATIENTS WITH SLEEP-POTENTIATED EPILEPTIFORM ACTIVITY}

René Andrade-Machado, Havana: Sánchez Fernández et al. ${ }^{1}$ reported that electrical status epilepticus in sleep (ESES) was more likely in patients with early developmental lesions that involved the thalamus. They demonstrated that early thalamic injury is associated with ESES.

We investigated 24 children with rolandic epilepsy and followed them for 6 years. ${ }^{2}$ The perfusion images were registered when an atypical evolution was diagnosed. Atypical features included continuous spikes and waves during non-REM sleep and cognitive deficits. Patients with atypical evolution of rolandic epilepsy showed a well-defined pattern of cerebral perfusion characterized by symmetric hypoperfusion at the level of thalamus without structural abnormalities in 6 out of 7 patients ( $72.4 \%$ vs $0 \%$ in typical variant). Only patients with bilateral and symmetric hypoperfusion in the thalamus were at risk for developing cognitive deficits and continuous spike and wave during non-REM sleep.

The authors' findings confirm ours as both suggest the potential role of the subcortical structuresspecifically the thalamus - as a source of synchronizing, oscillatory activity during non-REM sleep and its role in cognitive deficits.

Author response: Iván Sánchez Fernández, Masanori Takeoka, Sanjay P. Prabhu, Sanjeev V. Kothare, Tobias Loddenkemper, Boston: We thank Dr. AndradeMachado for his thoughtful comments. In our series, ${ }^{1}$ 
early thalamic lesions were particularly frequent in patients with sleep-potentiated epileptiform activity. However, more than half of the patients with sleep-potentiated epileptiform activity did not show gross abnormalities on review of the structural MRIs. Minor structural changes or functional abnormalities in the thalamus and related circuitry may account for these cases. The authors' results are very interesting as they support our hypothesis of a thalamic involvement and are also concordant with perfusion changes of the thalamus in patients with generalized spike-waves on functional MRI studies. ${ }^{3-5}$ In another study, the authors ${ }^{2}$ suggest a thalamic hypoperfusion in patients with sleeppotentiated epileptiform activity. Confounders such as variability in age, gender, duration, and severity of epilepsy, as well as validity of SPECT and AMRI for the functional assessment of deeper structures, need to be confirmed in larger series. However, these findings may provide additional evidence for functional changes in deeper structures and potential involvement of cortico-thalamic circuitry in patients with sleep-potentiated epileptiform discharges.

(C) 2012 American Academy of Neurology

1. Sánchez Fernández I, Takeoka M, Tas E, et al. Early thalamic lesions in patients with sleep-potentiated epileptiform activity. Neurology 2012;78:1721-1727.

2. Andrade Machado R, Garcia Espinosa A, Perez Matos JF, et al. Patrones de Perfusin Cerebral en la Epilepsia Rolandica: formas tipicas y atipicas. Rev Ecuat Neurol 2011;20:1-3.

3. Siniatchkin M, Groening K, Moehring J, et al. Neuronal networks in children with continuous spikes and waves during slow sleep. Brain 2010;133:2798-2813.

4. Aghakhani Y, Bagshaw AP, Benar CG, et al. fMRI activation during spike and wave discharges in idiopathic generalized epilepsy. Brain 2004;127:1127-1144.

5. Benuzzi F, Mirandola L, Pugnaghi M, et al. Increased cortical BOLD signal anticipates generalized spike and wave discharges in adolescents and adults with idiopathic generalized epilepsies. Epilepsia 2012;53:622-630. 


\section{Neurology}

\section{Early thalamic lesions in patients with sleep-potentiated epileptiform activity}

Barbara S. Connolly, Iván Sánchez Fernández, L.K. Prashanth, et al. Neurology 2012;79;2218-2219

DOI 10.1212/01.wnl.0000423466.65431.4a

This information is current as of November 26, 2012

\section{Updated Information \&} Services

References

Permissions \& Licensing

Reprints including high resolution figures, can be found at: http://n.neurology.org/content/79/22/2218.2.full

This article cites 5 articles, 1 of which you can access for free at: http://n.neurology.org/content/79/22/2218.2.full\#ref-list-1

Information about reproducing this article in parts (figures,tables) or in its entirety can be found online at:

http://www.neurology.org/about/about_the_journal\#permissions

Information about ordering reprints can be found online:

http://n.neurology.org/subscribers/advertise

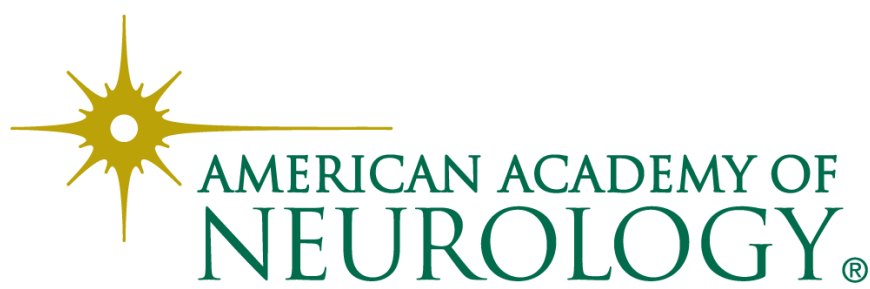

